\section{$\underset{\substack{\text { hommes } \\ \text { \& migrations }}}{ }$}

\section{Hommes \& migrations}

Revue française de référence sur les dynamiques

migratoires

1333 | 2021

L'enfance en exil

\title{
Christine de Mazières, La Route des Balkans
}

Paris, Sabine Wespieser, 2020, 184 p., $18 €$.

\section{Mustapha Harzoune}

\section{(2) OpenEdition}

1 Journals

\section{Édition électronique}

URL : https://journals.openedition.org/hommesmigrations/12768

DOI : 10.4000/hommesmigrations. 12768

ISSN : 2262-3353

\section{Éditeur}

Musée national de l'histoire de l'immigration

\section{Édition imprimée}

Date de publication : 1 avril 2021

Pagination : 223-224

ISBN : 978-2-919040-55-1

ISSN : $1142-852 X$

Référence électronique

Mustapha Harzoune, "Christine de Mazières, La Route des Balkans », Hommes \& migrations [En ligne], 1333 | 2021, mis en ligne le 01 avril 2021, consulté le 26 juillet 2021. URL : http://

journals.openedition.org/hommesmigrations/12768; DOI : https://doi.org/10.4000/

hommesmigrations. 12768 


\section{La Route des Balkans}

Christine de Mazières, Paris, Sabine Wespieser, 2020, 184 p., $18 €$.

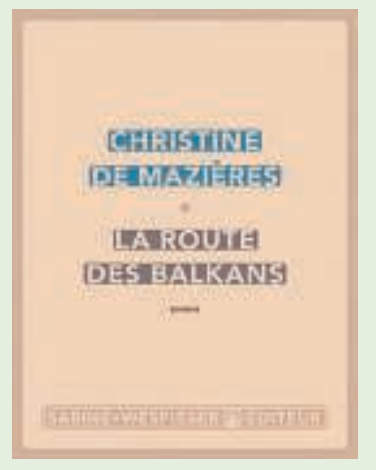

Personne n'a oublié ces images terribles du petit Aylan échoué sur une plage turque. Le corps sans vie de l'enfant a ému la terre entière. Le temps d'un reportage. Ce qui était prévisible. Mais qu'en est-il de ceux que l'on ne voit pas? Qu'en est-il de ces dizaines, de ces centaines d'enfants partis sur les routes de l'exil et qui jamais n'arriveront à

destination. Partis, qui d'Afghanistan, qui de Syrie, ils sont sur la route. Ici, la route des Balkans. Ils s'appellent Asma, amoureuse de poésie, et Lefana, sa sœur, les deux jeunes syriennes, les Afghans se prénomment Tamim, sa famille est hazara (chiite), il a 14 ans et doit fuir, seul, pour échapper à la mort; Khaled, le boulanger, a 18 ans; Saleh, le tailleur, 17 ans; Hamid, le berger, 16 ans; Fazal prétend avoir 15 ans mais personne ne le croit.

Pour un enfant, une femme, un homme qui parviennent à rejoindre le pays visé, combien de corps noyés, morts de froid ou d'épuisement, violentés par des «trafiquants d'hommes» ou par les polices. Et la «victoire» efface-t-elle les horreurs, le calvaire enduré?

Efface-t-elle ces mois et ces années sur les routes, les chemins de boue et de neige, les détours et les retours, les arnaques et les vols, l'esclavage, la mort frôlée plus d'une fois? Efface-t-elle le souvenir de celles et de ceux perdus sur ces chemins de mort, qui tombé d'un échafaudage, qui se laissant mourir dans la neige, qui stoppé par la balle d'une patrouille turque, qui noyé, ou ce corps décomposé dans un camion frigorifique avec 70 autres malheureux. Oui, pour celles et ceux qui touchent au but, «la victoire est amère». Le voyage "a le prix de la mort»: "combien de morts laissés au bord des routes et au fond de la mer, combien de chers disparus dans le cour de chacun!»

C'est cela que raconte Christine de Mazières dans ce livre en forme de roman. Roman réaliste et documenté. Il raconte les ombres des temps modernes à hauteur de ces enfants quand média et polémistes bataillent, sous les projecteurs et grassement, à coups de statistiques, d'idéologie et d'arguments de comptoir. Le tour de force de ce récit tient autant à la sensibilité, sans pathos, de l'écriture qu'à son architecture, où, par touches, les éléments - personnages, lieux, événements -, d'abord épars, se rapprochent, 
convergent, s'assemblent, pour faire sens. Tout progresse avec habileté et doigté. Attention: ce livre est intelligent.

Christine de Mazières a monté un scénario de série: alors que les jeunes progressent sur cette route des Balkans, ailleurs en Europe, le texte (la caméra) plonge sur d'autres personnages: Radomir le Bulgare désargenté; Bernard Gruber, inspecteur des autoroutes du Burgenland en Autriche, à la frontière de la Hongrie; Jürgen Fest, le chef de la police scientifique de Haute-Autriche; Alma, l'étudiante en histoire, bénévole pour aider les réfugiés. Et Helga, une Allemande de 75 ans. Une «artiste de la vie» (Lebenskünstlerin) qui cache de vieilles douleurs derrière sa joie de vivre. Et il y a la scène politique européenne. D'un côté, Orban, de l'autre, Angela Merkel. Nous sommes en 2015. Christine de Mazières brosse sans doute le plus beau portrait qui soit de la chancelière - seule, alors, à incarner les valeurs européennes, seule face aux lâchetés des hommes politiques. En 2015, le courage d'une grande dame rencontrait le rêve des réfugiés. L'urgence alors était d'éviter une catastrophe humanitaire. "Wir schaffen das», «nous y arriverons» et elle y est arrivée: «Elle ne fait plus de diplomatie, encore moins de politique à cet instant. [...] Elle s'engage réellement. Il est, dans la vie, de rares instants de vérité. En voici un. » Angela Merkel était au rendez-vous.

L'histoire allemande fait qu'Helga connaît bien cette route des Balkans. Hier aussi, il fallait «sauver sa peau, c'est la seule chose qui comptait alors». Pour elle alors, l'Europe fut un rêve, "ce désir de fraternité et de liberté». 1945, 1989 ou 2015, l'Europe ce devrait être "accueillir ceux qui viennent chercher la liberté». Et l'allegretto de la $7^{\mathrm{e}}$ de Beethoven qui retentit, comme un retour à la vie. Une renaissance.

M. $\mathrm{H}$. 